\title{
90-Ton Triple Cylinder Jack Design
}

\author{
Engineering Note \#3740.520-EN-186
}

Issued: Sept. 26, 1988

Originator: Al Jaques

Checked: GMn. 
D-Zero Engineering Note

3740.520-EN-186

Issued $9 / 26 / 88$

\title{
90-Ton Triple Cylinder Jack Design
}

\author{
Al Jaques
}

\section{Problem History}

The three D-Zero cryostats (2 EC and $1 \mathrm{CC}$ ) will rest on three carriages which in turn ride on a set of hardened ways in the center beam. A pair of Tychoway rollers will be fitted to each of the four corners of the three carriages to provide the rolling support. In the final design, the two EC cryostats will be able to roll out and away from the CC cryostat in order to provide access to the space between each cryostat for maintenance and repairs. The cryostat will be frequently accessed, about once a month, during a collider run.

The heaviest cryostat weighs about 360 tons. The large roller weight in one position for such a long period of time, created a concern about the rollers dimpling the hardened ways or even suffering permanent deformations themselves. There is also the possibility that the vertical position of the cryostat will need to be adjusted to align it with the beam line or that the carriage and cryostat will have to be lifted to remove and service the rollers. A device or system was needed to 1) relieve the weight of the cryostats from the rollers and the hardened ways, and 2) minimally adjust the vertical position of the cryostats, if necessary, and/or service the rollers.

\section{Design Constraints}

Compact hydraulic jacks seemed to be the answer. The first and foremost criteria was capacity. It was desired that the jacks be rated to twice the actual load. A jack is to be placed beside each roller, giving a total of eight per cryostat. The load per jack for a 360 ton cryostat would then be 45 tons, leaving 90 tons as the required capacity.

The second and equally important criteria to be met was size. After installation of the Tychoway rollers, room to mount these jacks is very limited underneath the carriage. The space surrounding the bottom of the carriage is cluttered with wiring and plumbing and thus further limits available space for the jacks. What was left was a $3.75^{\prime \prime} \mathrm{X} 6.0625^{\prime \prime} \mathrm{X} 12.25^{\prime \prime}$ rectangular envelope on each side of a pair of rollers (see Appendix A).

\section{Procurement}

A preliminary jack design was drawn up to present to prospective jack manufacturers. Five manufacturers were contacted, three responded 
positively to the proposal. Enerpac, OTC and Ram-Pac International, a subsidiary of Hader Industries, were sent a print of our design and a list of specifications. Each came back with a proposal and quote. Initially, Ram-Pac and OTC proposed taking three of their 30-ton, single cylinder; units and joining them via a single manifold or by using face seals between each jack and bolting the three together with long connecting rods. These approaches were discarded, eventually, due to increased chances of leakage (more seals) and a greater possibility of skewing the three pistons in a three unit design. All three manufacturers settled on a triple cylinder, monoblock design.

The three proposals were similar except for the fact that Ram-Pac chose to make their design spring return instead of double-acting as Enerpac and OTC did. The reason for this was given that the cavity which contained the spring would be used as a reservoir to catch any leakage past the primary and secondary seals (polypaks). The third seal, on the piston rod, would likely never see any liquid pressure unless the first two plunger seals failed. The three cavities are connected within each jack with $1 / 4^{\prime \prime}$ lines and then plumbed externally to a separate sump for spill off. If a leak were to occur in the first two seals, the cavities would fill and then drain into the sump by gravity, thus the third seal would see little pressure. The double-acting cylinders would always place liquid pressure on the third seal increasing the chances of leakage, to the outside.

After ironing out such details as bolt holes, port holes, fluid line diameters, etc., a manufacturer decision was made. Ram-Pac's proposal was the most economical by far, at only $60 \%$ of the next lowest quote. The quote was $\$ 1600$ apiece if delivered in quantities of 10 or $\$ 1295$ apiece if delivery of all 28 was desired. It was decided to order all 28 jacks $(24$ required +4 spares) at once. Before the money was committed, however, Ram-Pac's capability had to be established.

\section{Justification for Noncompetitive Procurement}

An afternoon visit to Ram-Pac/Hader Industries' facilities in Pewaukee, Wisconsin by Al Jaques, Mechanical Support, and George Mulholland, D-Zero Group, reassured us that Ram-Pac has the ability and equipment to meet our specification for the jack design. A trip report on the Ram-Pac facility is documented in Engineering Note 3740.520-EN-184.

Fermilab has dealt with Ram-Pac/Hader Industries previously through Herm Stredde, D-Zero Group. In the past year and a half, a total of $\$ 120,000$ was spent on 16 hydraulic cylinders used to support the entire D-Zero detector assembly. There were some initial weld leaks but they were repaired once Ram-Pac was notified. The cylinders have been trouble-free since. Specifics of these purchases are also documented in the trip report.

Due to Ram- Pac's small size and flexibility, they will be able to deliver the jacks 30 to 60 days sooner than OTC or Enerpac. The time frame given was 90 to 120 days from the receipt of order.

With their credibility and ability established, the order for 2890 -ton, single block, triple cylinder jacks was placed with Ram-Pac ( $\$ 36,260$ total). A copy of 
the purchase requisition and all accompanying documents is shown in Appendix B. 
Appendix A 


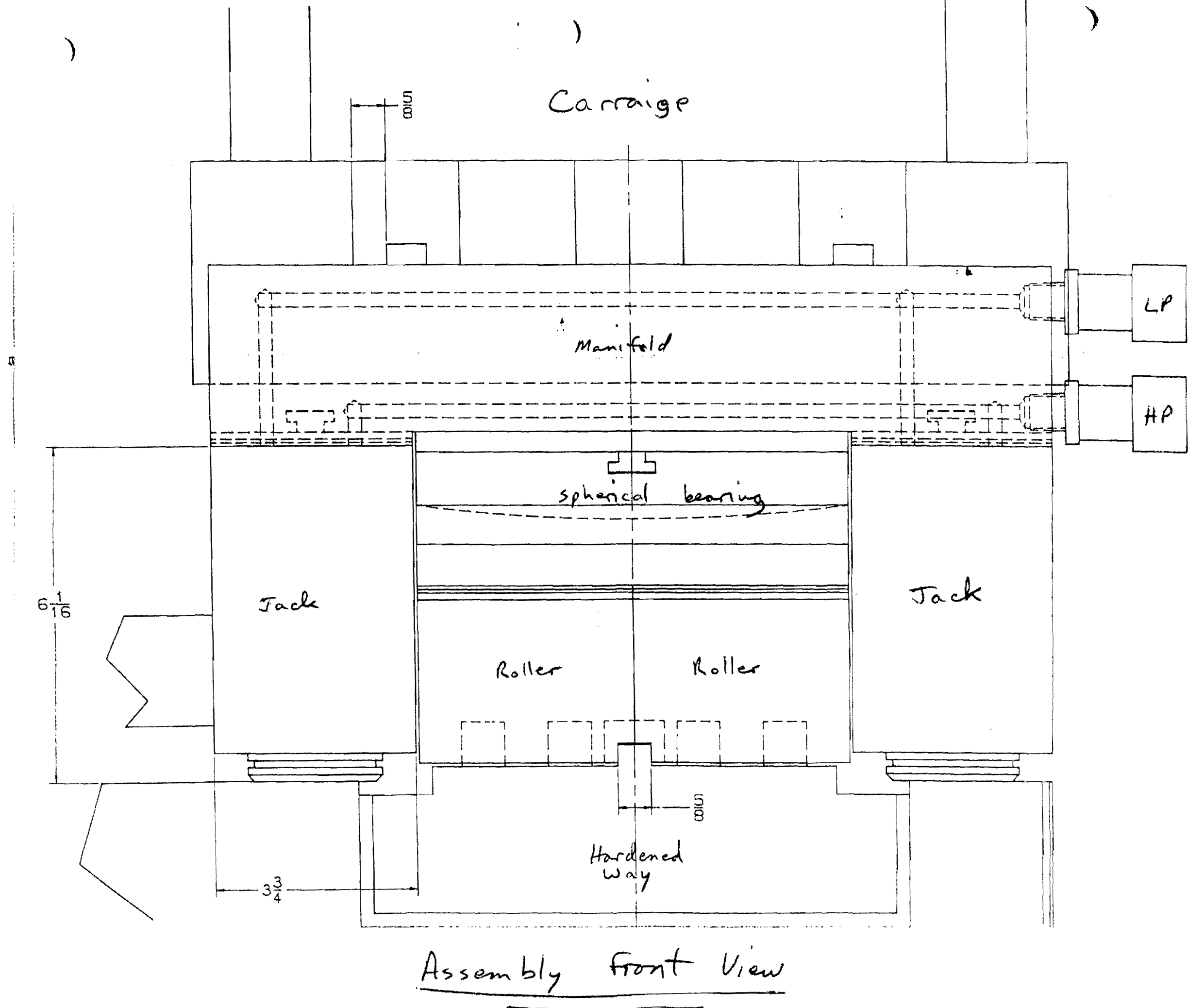




\section{Hydraulic Jack Schematic}

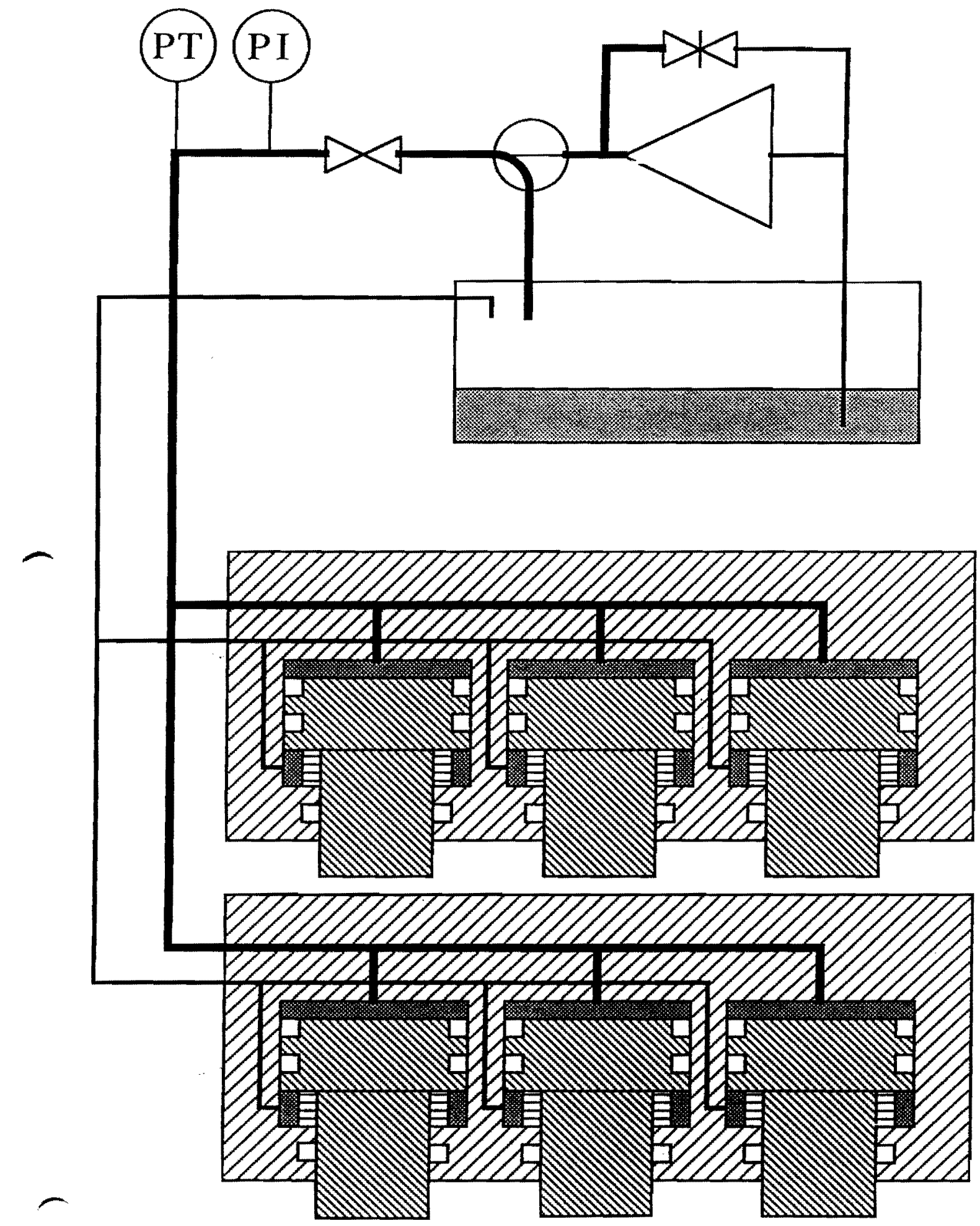

GTM 9/12/88 
Appendix B 
P.O. BOX 500

BATAVIA, ILLINOIS 60510

TELEPHONE: $312 / 840-41 \epsilon$

TWX: 9102303233

TELEX: 720481

FAX $\$ 312-840-2457$

\section{REQUEST for QUOTATION}

RAM-PAC IFTKRMATIONAL

N27 W23015 ROUTDY DRTVE

P.0. BOX 27

PEWAUKRE, WT 53072-0027

$$
\begin{aligned}
& \text { date September 9, } 196 \\
& \text { OUOTAIIONNO } \frac{6414-1 \text { HOV }}{5: 00 \text { PH CS }} \\
& \text { OUOTATION S CLOSE 09/26/88 } \\
& \text { ISEE LATE BID CAITERIA ATTACHEO } \\
& \text { PAGE } 1 \text { OF } 1 \text { pages }
\end{aligned}
$$

\begin{tabular}{|c|c|c|c|c|c|}
\hline ITEM & ory. & OESCAIPTION & UNIT PAICE & $\begin{array}{l}\text { TOTAL } \\
\text { NET PAICE }\end{array}$ & OELIVEAY \\
\hline 1. & $28 \mathrm{BACH}$ & 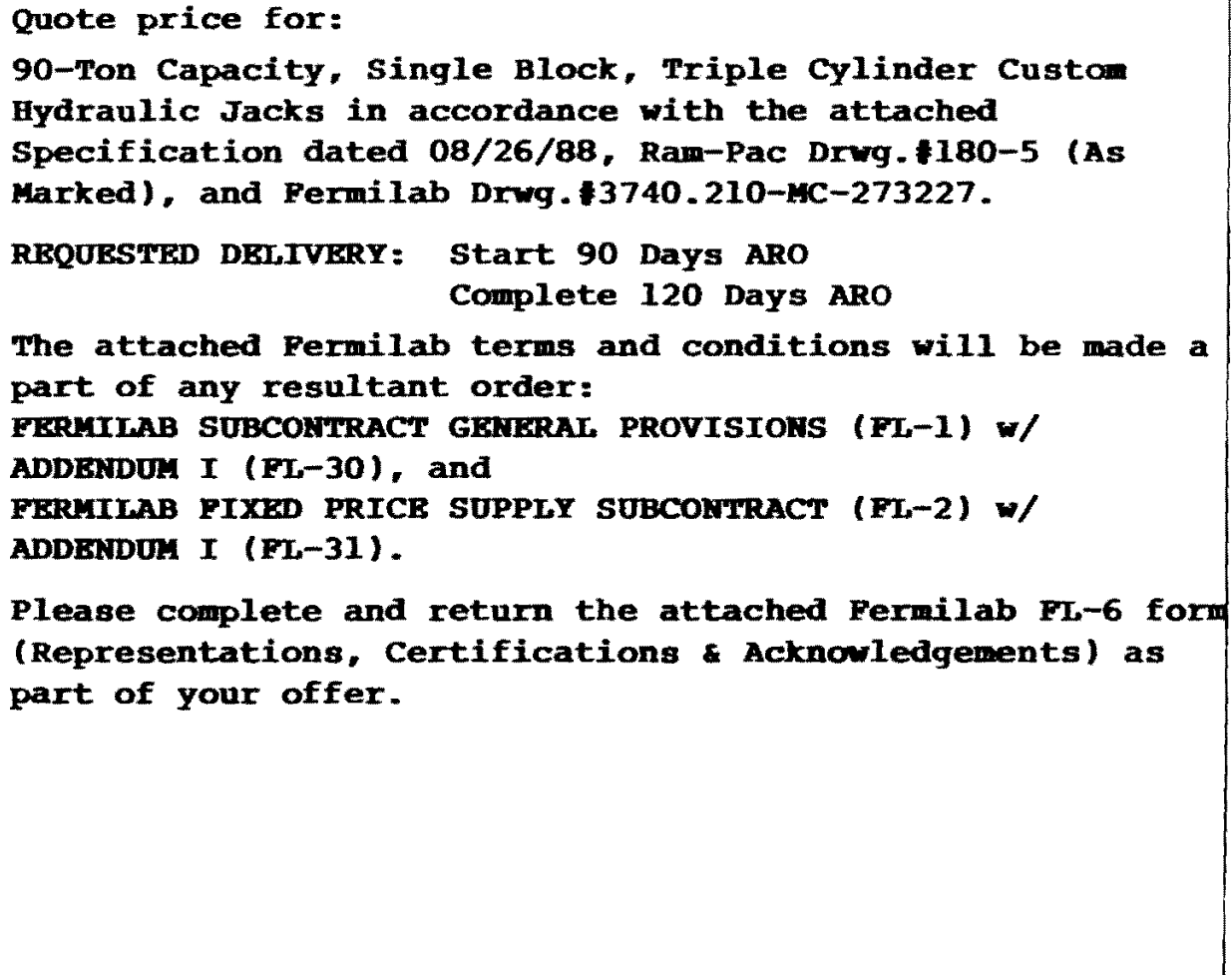 & $\$$ & & \\
\hline
\end{tabular}

TFIMS

DAF SUBMITIEO

T
MATERIALS. SUPPLIES OA SERVICE RESUITING FROM TMIS OUOTE ARE FOA WOAK DONE UNDER PRIME CONTRACT DE.AC02.76CHO3000 WITM THE UNITED STAIES OEPARTMENI OF ENERGY

ANY ITEMS COVERED OY GSA CONTRACIS SHOULO GE SO INOICATEP

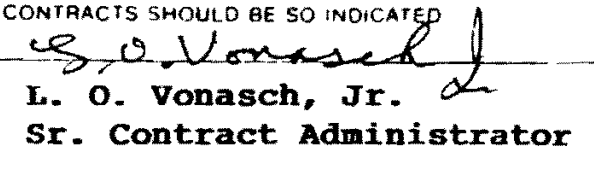

ay 


$$
\begin{gathered}
\text { DO } 90 \text { Ton Triple Jack } \\
\text { Specifications } \\
\text { Al Jaques } 8 / 26 / 88
\end{gathered}
$$

1. The jacks will have a 90 ton capacity and be able to withstand pressures up to 10,000 psi without leakage.

2. The jacks will be capable of being onergized for up to 6 months at a time.

3. All pipe plugs will be provided.

4. 0-rings for the high pressure and drain return grooves will be provided.

5. The jacks will meet all necessary dimensions and specifications of Fermilab drawing number 3740.210-MC-273227.

6. Delivery of 28 completed jacks will occur within 90 to 120 days after receipt of order.

7. High pressure seals will be dual "Polypaks".

8. A low pressure "Polypak" seal will make a sump return volume between the piston and the plunger, and those volumes manifolded to a drain port.

9. The piston rod will be protected by a wiper seal.

10. All materials will be suitable to their service.

11. The piston will spring retract when not pressurized.

12. Each plunger will be fit with a 5 degree swivel cap.

13. A checked and approved manufacturing assembly drawing is to be supplied before manufacture.

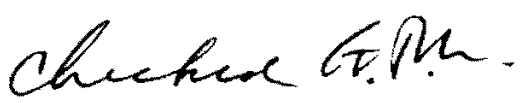

